\title{
Meta-affective learning in an introductory physics course
}

\author{
Jennifer Radoff ${ }^{1}$, Lama Z. Jaber ${ }^{2}$, and David Hammer ${ }^{1}$ \\ ${ }^{1}$ Department of Education, Tufts University, 12 Upper Campus Road, Paige Hall, Medford, MA, 02155 \\ ${ }^{2}$ College of Education, Florida State University, 2208M Stone Building, Tallahassee, FL, 32304
}

\begin{abstract}
We interviewed a college freshman engineering student, "Marya," after she completed her first semester in a reformed introductory physics course. We found that she experienced a drastic shift in her feelings and approach to learning physics. In particular, she first felt anxious about not knowing the right answer, but as she came to see physics as a sense-making pursuit, she felt at ease and eventually excited to approach a new and unknown challenge. In this paper, we introduce the construct of meta-affective learning, and illustrate it using data from Marya's interview and coursework. Finally, we argue that meta-affective learning was an important part of Marya's physics learning that persisted long past her completion of the course.
\end{abstract}

\section{INTRODUCTION}

Since the inception of Physics Education Research (PER), many efforts have focused on supporting students' conceptual understanding of canonical content knowledge. Over the last few decades, however, the science education community has moved beyond the notion that science learning is solely about content knowledge acquisition. In particular, many have argued to promote students' engagement in authentic disciplinary pursuits and practices $[1,2]$. This push has included efforts to focus on students' epistemologies - their beliefs about knowledge and learning [3] — and on students' epistemic affect — their feelings about and within the doing of science [4]. This work has enabled the PER community to develop a more holistic and complex understanding of what constitutes learning in physics.

We aim to contribute to this work by studying the case of Marya - a freshman engineering student who dramatically changed her feelings and approach to learning after having taken an introductory physics course. We contend that Marya's learning was both meta-affective - in her feelings about feelings - and epistemological - in her understanding of knowledge and learning. Here, due to space limitations, we focus on illustrating the meta-affective dimension, but in a forthcoming paper [5] we discuss the entangled dynamics between meta-affect and epistemology in Marya's learning.

In mathematics education, DeBellis and Goldin [6] propose the construct of meta-affect to characterize how someone can experience a generally undesirable emotion as pleasurable and thrilling. For example, knowledge of safety can render the fear of a roller coaster ride exhilarating rather than terrifying. Similarly, we'd like students to experience feelings such as unease, uncertainty, and confusion in productive ways. These generally undesirable feelings, when coupled with the knowledge that science is about exploration and sense-making, may elicit the "anticipation of possible elation at understanding something new, or achieving a difficult goal. Then frustration itself is experienced as interesting, curious, even euphoric" [6].

When students begin to elicit these productive feelings stably over time, we call it meta-affective learning. We refer to it as meta-affective rather than merely affective, because it describes a change in how one experiences epistemic feelings [4] such as uncertainty and confusion, rather than eliminating those feelings altogether. Marya's case provides evidence that this kind of meta-affective learning is possible and gives us insight into how it may support long-term scientific engagement.

\section{METHODS}

Marya was enrolled in the spring semester of an introductory calculus-based mechanics course taught by Hammer. Radoff was her TA. The course was designed according to the notion that "the whole of science is nothing more than a refinement of everyday thinking" [7], whereby students worked to build and refine their own knowledge from everyday experiences, examine and articulate their confusion, and communicate their reasoning clearly. The course structure supported this work: In weekly problem sets and exam short-answer questions, students got credit for good reasoning regardless of having the correct answer; in labs, students completed a challenge by designing and conducting their own experiments.

We noticed Marya's shift from appearing visibly anxious during the first exam to reportedly wanting to minor in physics, so we asked to interview her about her experiences in the course. Jaber, who was not affiliated with the course, interviewed Marya immediately after the course was over. We then transcribed and analyzed the interview, identifying excerpts where Marya reflected on her changing approach toward and feelings with respect to learning and doing science. Radoff also interviewed Marya two years later, 
when she was a junior. In addition to the interview data, we also had copies of students' written work collected for a larger project studying students' engagement and persistence in science [8].

In what follows, we provide excerpts from Marya's first and second interviews as well as a sample of her written work to illustrate Marya's meta-affective learning.

\section{DATA AND ANALYSIS}

\section{A. Excerpts from Marya's first interview}

When Marya reflected on her experiences in the course during her first interview, she attributed her initial feelings of anxiety to not knowing the right answer:

Definitely not knowing, at first, was such a huge factor in causing anxiety because it was just always like you don't know! And the chances are for most part nobody's gonna give you the answer.

But she described how slowly, her anxiety began to disappear:

But physics, even though it caused anxiety, it started not causing anxiety...it was more fueling a weapon against anxiety than fueling the anxiety itself.

How did this happen? Marya described this metaaffective shift as deeply entangled with her changing sense of what it means to learn and do physics-i.e., her epistemology:

And all that because I think it was more about the process, it was just really about learning... it wasn't about absolute right or wrong. [...] Rather than being intimidated by what you don't know, it's just like, work on what you do know and add to it.

She began to associate not knowing the right answer with having an exciting challenge to pursue:

This whole anxiety about not knowing, it disappeared and it was like, 'Oh, I don't know, but ok, we can work it out,' you know? And if we don't, then we have a question that we're just gonna have to wonder about...If I don't know the answer then, 'Oh goody we have another problem to solve!'

Eventually, each new problem held the promise of discovery, which elicited feelings of elation and joy:

When you're an engineer you have no shortage of problems to deal with. And just like, this idea of like, 'Oh, we have this big problem,' you know, and it's like so complex. And it's scary but it's also exciting because it's like, 'Let's see if we could figure this out,' you know? And when you do, it's so rewarding in the end because like it's just, I don't know, it's such a high when you figure something out, you're just so excited and just like I dunno- you see the smile on my face!

Though Marya's anxiety did not completely disappear, her excitement to sense-make took precedence:

Yes, there is the anxiety about physics and like can I do it? and it's difficult and can I handle that difficulty? But then, you go and figure something out about inelastic collisions, for example, and you're so excited, it's like a kid walked into a candy store, and you're like, 'You know what? Who cares? The anxiety can just like take a back seat because physics is just too awesome to pass up.'

\section{B. An example from Marya's written work}

Marya's comment above, about figuring "something out about inelastic collisions," refers to a problem from her homework (Figure 1), assigned about halfway through the semester that read: "A $1 \mathrm{~kg}$ cart, rolling at $6 \mathrm{~m} / \mathrm{s}$, collides with and sticks to an identical cart that's initially at rest. So, after colliding, the carts roll together as a single, $2 \mathrm{~kg}$ unit. How fast does the pair of carts roll?" The problem went on to ask about the kinetic energy of the carts before and after the collision, and then asked students to do the problem again with a $2 \mathrm{~kg}$ cart initially at rest.

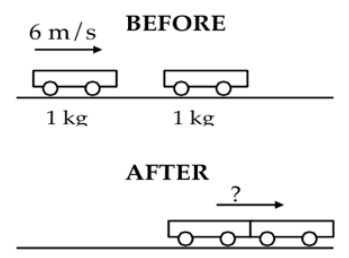

FIG. 1. An inelastic collision.

Most students approached this problem without much interest. Marya, however, used this problem as an opportunity to sense-make. After calculating what the problem asked for, Marya used these particular cases to derive a generalized relationship between the relative masses and the amount of kinetic energy lost in the collision. She wrote:

Interesting! So it seems that when the cart collides with an object with the same mass, half the initial kinetic energy is lost. When it collides with an object twice its mass, two thirds of the KE energy will be lost. So there's a relationship between the KE lost and the fraction of the mass of the stationary object and the total mass of the system. Specifically,

$\mathrm{KE}_{\text {lost }}=\mathrm{KE}_{\mathrm{i}} \times\left(\mathrm{m}_{\text {stationaryObject }} / \mathrm{m}_{\text {totalSystem }}\right)$ 
She then double-checked that this expression was true for a third system of masses with a $4 \mathrm{~kg}$ stationary cart. She reflected on her findings:

So the relationship holds true!! From this expression we can also infer that the system will always have a quantity of $\mathrm{KE}$ after collision. However, as the stationary object gets larger and larger, the kinetic energy will start becoming negligible. In other words, the stationary object will always have a velocity but if its large enough, the velocity becomes so small that we can safely say that the stationary object remains stationary for the most part to our naked eyes.

Here, we see Marya using the formal mathematical relationship she derived to deepen her understanding of energy conservation and transfer. She checked her formal derivation with her experience of the real world and reasoned that there must always be some amount of remaining kinetic energy in the system that gets less visible as the stationary object gets more massive.

Marya engaged this problem in a way instructors hope all students would. She oriented to it, not as routine plug-nchug, but as an opportunity to build new knowledge. Furthermore, we see evidence throughout Marya's solution of her deep engagement and enjoyment for figuring out something new. Not only did Marya go many steps beyond what is required of her by the assignment, but we can see in her abundant use of exclamation points that she was excited about what she had discovered.

The way Marya approached and felt about this assignment marked a stark contrast with the anxiety we had witnessed earlier in the semester. Not only had she begun to actively sense-make, but she did so with an eagerness we had not initially seen in her work or general disposition. Not surprisingly, this moment was salient for her as well. She reflected on this moment in her first interview:

I remember there was this problem set where I figured something out about inelastic collisions and kinetic energy. And it was just like this natural conclusion from something, like the question, but I took it just a tiny little bit further and I reached this conclusion and I was completely sure that it was a valid conclusion to make. And I got so excited and like I wrote like there where like tons of exclamation points because I was just so excited.

In this way, Marya's excitement for and within sense-making moments supported her meta-affective learning.

Next, we present excerpts from Marya's second interview, two years after taking the course, to see the longterm impact of Marya's meta-affective learning.

\section{Excerpts from Marya's second interview}

When Radoff met with Marya to interview her a second time, Marya was in her junior year. She did not end up minoring in physics because of time and program constraints, but she began working in an environmental engineering lab as an undergraduate research assistant. In fact, she wanted to pursue a doctorate in engineering so that she could do research full-time. When Radoff asked what excited her the most about research, she said:

I think it's figuring out the answers despite the confusion. I think that's really fun. You know, to go from looking at something and be like, I have no clue what's going on, to being going like, Oh, I know what's going on. I think that's great. Like, that literally makes me giggle and jump.

From here we see that Marya did not just learn how to cope with and tolerate feelings of uncertainty and confusion, but those very feelings inspired her choice to pursue a career in research.

To be clear, we do not mean to romanticize either Marya's experience or the work of scientific research. Marya never stopped feeling confused or uncertain. She spoke of feeling frustrated at times:

Struggling is not always fun. Like there's the frustration, like, 'Oh my god, like really this makes no sense.' And then you sit with it for a while, or you leave it, and like you storm out of the room and you come back in and you sit with it and you think and you figure it out and you come up with different solutions, and some work some don't, but then at the end of the day, you come up with a tangible thing to say about your confusion. It's either like, $\mathrm{Oh}$, I figured out what this means, or I figured out what I don't understand.

What we want to highlight is how Marya interpreted and experienced those moments of frustration. Rather than making her feel anxious or defeated, those moments became opportunities for sense-making. Figuring out and articulating what she doesn't understand is not a marker of failure, but a scientific achievement in its own right.

When Radoff asked Marya about whether her freshman physics course has informed the ways in which she thinks about things now, she said:

I cannot even begin to like- honestly it influences a lot- I think a lot about what I've been taught in the class- and it's not the physics- I mean the physics is great, I love physics... [but] what I've learned from that class in terms of handling confusion, accepting confusion, the idea of building the stamina for confusion...it gave me a really successful framework to think. 
Here, Marya's account highlights the lasting power of her meta-affective learning, which she explicitly elevated in relation to her content learning. Though we did not follow her into the lab to see how it was enacted in situ, she has clearly carried around the perception of her own learning "outcome" as a change in feelings and orientation toward confusion.

\section{CONCLUSIONS}

In this paper, we illustrated Marya's meta-affective learning evident both in her own account as well as in an instance of her sense-making. From our perspective as physics educators and from Marya's own perspective, her meta-affective learning was a fundamental part of her physics learning more generally. Marya's case is only one example of meta-affective learning, but it provides proof that such learning is possible. It also illustrates the lasting impact meta-affective learning can have on an individual's academic growth and professional choices.

It is important to note that we do not wish to separate meta-affective learning from the other dimensions of learning physics (conceptual, epistemological, social, etc.). On the contrary, in the forthcoming paper featuring this work
[5] we look at the ways that Marya's meta-affective and epistemological development dynamically co-constructed one another. This paper highlights meta-affective learning as an important part of the larger picture-one that has until now been under-represented if not completely unacknowledged in PER. Recognizing meta-affective learning as part of learning physics means that we must continue to shift our focus past content goals and outcomes in both research and instruction. While making practical recommendations for instruction is beyond the scope of this paper, we hope that this work will continue to expand the boundaries for how the PER community conceptualizes learning in physics and will motivate others to find and study more cases of students' meta-affective learning.

\section{ACKNOWLEDGMENTS}

Special thanks to Marya for continuing to inspire our research and our own disciplinary journeys. We also thank Anna Phillips for her feedback on a draft of this paper. This work is funded by the Gordon and Betty Moore Foundation, Grant GBMF3475. The views expressed here are those of the authors alone.
[1] R. A. Duschl, H. A. Schweingruber, and A. W. Shouse "Taking Science to School: Learning and Teaching Science in Grades K-8," Committee on Science Learning, Kindergarten Through Eighth Grade. Report of The National Academies Press (2006).

[2] National Research Council, “A Framework for K-12 Science Education: Practices, Crosscutting Concepts, and Core Ideas," Report of The National Academies Press (2011).

[3] D. Hammer and A. Elby, "Epistemological resources and framing: A cognitive framework for helping teachers interpret and respond to their students' epistemologies," In Personal epistemology in the classroom: Theory, research, and implications for practice, L. D. Bendixen and F. C. Feucht (Eds.), (2010).
[4] L. Z. Jaber and D. Hammer, "Engaging in science: A feeling for the discipline," J of the Learning Sc. 25, 2 (2016).

[5] Radoff, J., Jaber, L. Z., \& Hammer, D. "“It's scary but it's also exciting': A case of meta-affective learning in science." (In preparation)

[6] V. A. DeBellis and G. A. Goldin, "Affect and MetaAffect in Mathematical Problem Solving: a Representational Perspective," Educ. Stud. Math. 63, 2 (2006).

[7] A. Einstein, "Physics and reality," J of the Franklin Institute, 221, (1936).

[8] The Gordon and Betty Moore Foundation, Grant \#3475, “The Dynamics of Learners' Persistence and Engagement in Science." 